\title{
Characteristics and Prognosis of Abdominal or Thoracic Aortic Aneurysm Patients Admitted to Intensive Care Units After Surgery Therapy: A Multicenter Retrospective Observational Study
}

\section{Qinchang Chen}

Sun Yat-sen University First Affiliated Hospital

Qingui Chen

Sun Yat-sen University First Affiliated Hospital

\section{Yanchen Ye}

Sun Yat-sen University First Affiliated Hospital

Ridong Wu

Sun Yat-sen University First Affiliated Hospital

\section{Shenming Wang}

Sun Yat-sen University First Affiliated Hospital

Chen Yao ( $\nabla$ yaochen@mail.sysu.edu.cn )

Sun Yat-Sen University https://orcid.org/0000-0003-0327-9599

\section{Research article}

Keywords: Thoracic aortic aneurysm, Abdominal aortic aneurysm, Critical Care, Prognosis

Posted Date: October 1st, 2020

DOI: https://doi.org/10.21203/rs.3.rs-77375/v1

License: (c) (i) This work is licensed under a Creative Commons Attribution 4.0 International License.

Read Full License 


\section{Abstract}

Background: Subsequent intensive care unit (ICU) admissions postoperatively are not rare for patients with abdominal or thoracic aortic aneurysm (AAA or TAA), but a large-scale investigation on these patients is absent. The study aimed to investigate the characteristics and prognosis of AAA or TAA patients admitted to ICU postoperatively.

Methods: Patients admitted to ICU postoperatively with a primary diagnosis of AAA or TAA were screened in the eICU Collaborative Research Database, which contained data from multiple ICUs throughout the continental United States in 2014 and 2015. Baseline characteristics and comorbidities and were investigated and factors associated with ICU mortality were explored using univariable logistic regression. Receiver operating characteristic (ROC) curve analysis was performed to evaluate the prognosis predictive performance of the widely used severity scoring system APACHE IVa.

Results: 974 patients including 677 AAA and 297 TAA patients admitted to ICU postoperatively were included finally. Compared with TAA, AAA patients had a significantly higher median age (72 versus 64 years). $10.19 \%$ AAA and $2.36 \%$ TAA patients suffered from rupture of aortic aneurysm, and $89.07 \%$ AAA and $84.51 \%$ TAA patients underwent elective surgery. Hypertension requiring treatment was the most common comorbidity ( $57.31 \%$ for AAA and $61.95 \%$ for TAA). TAA patients had significantly higher ICU mortality $(9.43 \%$ versus $2.36 \%)$ than AAA. Several factors were found to be significantly associated with ICU mortality, including urgent surgery, rupture of aortic aneurysm, TAA, and a higher APACHE IVa score on ICU admission. APACHE IVa showed a good predictive performance for ICU mortality with an area under the ROC curve of $0.9176(95 \% \mathrm{Cl} 0.8789-0.9390)$.

Conclusions: Prognosis of aortic aneurysm patients admitted to ICU postoperatively is yet to improve, and factors associated with prognosis are mainly related to the condition itself. APACHE IVa can be used for prognosis prediction.

\section{Introduction}

Aortic aneurysm (AA) is the enlargement of the aorta defined as a segmental, full-thickness dilation of the blood vessel having at least a $50 \%$ increase in diameter compared with the expected normal diameter ${ }^{1-3}$. It usually located in the abdominal aorta, but can also be located in the thoracic aorta. AA usually causes no symptoms, however, it is with an increased risk of aortic rupture due to weakness in the wall of the aorta and could be fatal when ruptured ${ }^{4}$.

As a clinically silent disease, the prevalence and incidence of abdominal aortic aneurysm (AAA) and thoracic aortic aneurysm (TAA) are not fully understood. AAA was reported to have a prevalence of $4-8 \%{ }^{5-}$ 8 and TAA was $0.16-0.34 \% 910$ in screening studies. The relatively low prevalence and incidence make it difficult to conduct researches with enough sample sizes to obtain evidence, while obviously it is very 
important to have a working knowledge of the characteristics and prognosis of AA to aid with clinical decision making.

In the past three decades, the greatest advance in the treatment of AA was the introduction of endovascular aneurysm repair (EVAR), which used stent grafts and caused a major paradigm shift in the field of AA surgery ${ }^{11}$. For elective AAA repair, the mortality is 3-5\% for open surgery, but decreases to 0.5 $2 \%$ for EVAR ${ }^{12-14}$. However, the overall prognosis of $A A$ is still not satisfactory, especially for ruptured AA. The 30-day and 90 -day all-cause mortality rates were reported to be $22.9 \%$ and $33.3 \%$ respectively for ruptured AAA patients after surgery therapy ${ }^{15}$. To further improve prognosis of AA, no doubt postoperative management should be improved ${ }^{16}$.

Although not all AA patients need intensive care unit (ICU) admissions after surgery therapy ${ }^{17}$, subsequent ICU admissions postoperatively at least are not rare for patients with AAA or TAA. A study from Denmark reported that $62 \%$ AAA patients after open AAA repair surgery had ICU stays $>24$ hours ${ }^{18}$. In order to further improve the management of AA patients admitted to ICU postoperatively, an overview of their characteristics and risk profiles of prognosis is needed. However, as far as we know, a large-scale investigation on these patients is absent. Therefore, the study aimed to investigate the characteristics and prognosis of AAA or TAA patients admitted to ICU postoperatively.

\section{Methods}

\section{Data source}

The study used data from the elCU Collaborative Research Database (version 2.0), which was made available largely by Philips Healthcare and collaborators at Massachusetts Institute of Technology (MIT) Laboratory for Computational Physiology ${ }^{19}$. It consisted of data of patients admitted to one of 335 critical care units at 208 hospitals that participated in the Philips eICU program throughout the continental United States in 2014 and 2015. The database is released under the Health Insurance Portability and Accountability Act (HIPAA) safe harbor provision. The re-identification risk was certified as meeting safe harbor standards by Privacert (Cambridge, MA) (HIPAA Certification no. 1031219-2). Access to the database was approved after completing the CITI "Data or Specimens Only Research" course. This study was exempt from institutional review board approval due to the retrospective design, lack of direct patient intervention, and the security schema for the re-identification risk.

\section{Study population}

Patients admitted to ICU postoperatively with a primary diagnosis of AAA or TAA were screened in the database. Data on primary diagnosis was extracted from the table "admissiondx" which contained the primary diagnosis for admission to the ICU per the Acute Physiology And Chronic Health Evaluation (APACHE) scoring criteria. AAA or TAA were identified based on structured text including "Aneurysm, abdominal aortic", "Aneurysm, abdominal aortic; with dissection", "Aneurysm, abdominal aortic; with 
rupture", "Aneurysm, thoracic aortic", "Aneurysm, thoracic aortic; with dissection", and "Aneurysm, thoracic aortic; with rupture". Detailed inclusion criteria were: 1) a primary diagnosis of AAA or TAA; 2) first ICU admission only (for patients who had more than 1 ICU admission during the same hospitalization); 3 ) admitted from operating room, recovery room, or post anesthesia care unit (PACU); 4) age $\geq 18$ years. Detailed exclude criteria were: 1) instead of "admit", patients with an ICU stay type of "stepdown/other", "readmit for undo", "pre-admit", "transfer", or "readmit"; 2) patients who had more than 1 hospitalization records in the database; 3 ) length of ICU stay is missing. Flow chart of the study population was presented in Figure 1.

\section{Baseline characteristics, comorbidities, and study outcomes}

The following baseline characteristics were collected from the database, including age, sex, ethnicity, body mass index (BMI, calculated by height and weight), year of the hospital discharge date, type of surgery (elective or not), type of AA (ruptured or not), type of ICU, admitted location, Acute physiology IVa score, APACHE IVa score, several lab parameters of the APACHE IVa scoring system, intubation, ventilation, and dialysis on the first day after ICU admission. Various comorbidities were also collected. ICU mortality was the primary outcome of the study. Length of ICU stay, hospital mortality, and length of hospital stay were also studied but only for description. All the variables above were extracted from the tables in the database, including "patient", "apachePatientResult", "apacheApsVar", and "pastHistory".

\section{Statistical analysis}

Continuous variables were presented as median ( $25 \%$ percentile $-75 \%$ percentile) and categorical variables were presented as number (percentage). Comparisons between groups were tested by KruskalWallis $\mathrm{H}$ test for continuous variables or Chi-squared test (or Fisher's exact test) for categorical variables. The study population was also categorized based on length of ICU stay ( $<2$ days, 2-7 days, and $\geq 7$ days) and study outcomes of each category was described. Factors associated with ICU mortality were explored using univariable logistic regression. Kaplan Meier curves for ICU mortality together with logrank test were employed to compare the survival distribution of AAA and TAA. Receiver operating characteristic (ROC) curve analysis was performed to evaluate the prognosis predictive performance of APACHE IVa. A P value less than 0.05 was considered to indicate statistical significance. Empower(R) (www.empowerstats.com; X\&Y solutions, Inc., Boston, MA, USA) and R software, version 3.4.3 (http://www.r-project.org; R Foundation for Statistical Computing, Vienna, Austria) were used for statistical analyses.

\section{Results}

Baseline characteristics and comorbidities of the study population

974 AA patients admitted to ICU postoperatively were included finally. Among them, 549 (56.37\%) were AAA, 59 (6.06\%) were AAA with dissection, and 69 (7.08\%) were AAA with rupture; 195 (20.02\%) were TAA, 95 (9.75\%) were TAA with dissection, and 7 (0.72\%) were TAA with rupture. As presented in Table 1, the 
median age of the study population was 70 (62-77) years and $74.54 \%(726 / 974)$ were male. Compared with TAA, AAA patients had a significantly higher median age (72 versus 64 years, $P<0.001$ ), and more patients were male $(79.17 \%$ versus $63.97 \%, \mathrm{P}<0.001) .10 .19 \%(69 / 677)$ AAA patients suffered from rupture of aortic aneurysm, but only $2.36 \%$ (7/297) for TAA patients. Proportions of patients who received elective surgery were broadly the same $(89.07 \%$ for AAA versus $84.51 \%$ for TAA, $P=0.046)$. TAA patients had significantly higher Acute physiology IVa score (41 versus $30, \mathrm{P}<0.001)$ and APACHE IVa score (52 versus $45, P<0.001)$ on admission compared with AAA patients, and more needed intubation $(45.45 \%$ versus $17.73 \%, P<0.001)$ or ventilation $(44.11 \%$ versus $20.38 \%, P<0.001)$.

Comorbidities of the study population were presented in Table 2. The 5 most frequent comorbidities for AAA were hypertension requiring treatment $(57.31 \%)$, diabetes $(16.10 \%)$, chronic obstructive pulmonary disease (COPD, 14.62\%), cancer (13.00\%), and myocardial infarction (11.82\%), while for TAA, the 5 most frequent comorbidities were hypertension requiring treatment $(61.95 \%)$, heart valve disease $(14.81 \%)$, renal insufficiency $(11.11 \%)$, diabetes $(10.44 \%)$, and congestive heart failure $(10.10 \%)$.

\section{Prognosis of the study population}

The overall ICU mortality for the study population was $4.52 \%$ (44/974), and the hospital mortality was $6.26 \%$ (61/974). Compared with AAA, TAA patients had significantly higher ICU mortality $(9.43 \%$ versus $2.36 \%, \mathrm{P}<0.001)$ and hospital mortality $(12.12 \%$ versus $3.69 \%, \mathrm{P}<0.001)$. Consistent result was observed in Kaplan-Meier survival curves for ICU mortality (Figure 2), which showed a poorer survival in TAA patients compared with AAA patients $(P=0.0072)$. When the study population was categorized based on length of ICU stay ( $<2$ days, 2-7 days, and $\geq 7$ days), patients with longer length of ICU stay had worse prognosis (Table 3 ).

\section{Factors associated with ICU mortality}

Several baseline characteristics were found to be significantly associated with ICU mortality in univariable logistic regression (Table 4). Elective surgery was associated with reduced risk of ICU mortality (Odds ratio (OR) $0.22,95 \%$ confidence interval (CI) $0.12-0.42$ ), while rupture of AA was associated with increased risk of ICU mortality (OR 3.31, 95\% Cl 1.53-7.18). Compared with AAA, TAA was associated with increased risk of ICU mortality (OR 4.30,95\% CI 2.29-8.08). Acute physiology score IVa (OR 1.05 per 1 score increase, 95\% $\mathrm{Cl}$ 1.04-1.06) and APACHE IVa score on admission (OR 1.05 per 1 score increase, $95 \% \mathrm{Cl}$ 1.04-1.06) were also associated with poor prognosis. However, no comorbidities were found to be significantly associated with ICU mortality (Table 5).

\section{Prognosis predictive performance of APACHE IVa}

As presented in Table 6, APACHE IVa on ICU admission showed a good predictive performance for ICU mortality with an area under the ROC curve (AUC) of 0.9176 (95\% Cl 0.8789-0.9390). Compared with AA patients without rupture, the predictive performance of APACHE IVa decreased in patients with rupture of 
AA (AUC 0.8795 versus 0.9158 ). TAA patients also saw a poorer predictive performance of APACHE IVa compared with AAA patients (AUC 0.8660 versus 0.9233 ).

\section{Discussion}

The study focused on AA patients who were admitted to ICU after surgery therapy and investigated characteristics and prognosis of these patients. Predictors associated with prognosis and prognosis predictive performance of the widely used severity scoring system APACHE IVa were also explored. The main findings of the study were: 1 ) there were some great difference in baseline characteristics and comorbidities between AAA and TAA patients who were admitted to ICU postoperatively; 2) prognosis of these patients is yet to improve, especially for TAA patients; 3 ) instead of comorbidities, factors associated with prognosis were mainly related to the condition itself; 4) APACHE IVa showed good prognosis predictive performance. Based on a relatively large sample size and the recent data (year 2014 and 2015), these findings provided an updated overview of AA patients (either AAA or TAA) admitted to ICU after receiving surgery therapy, which might help to improve postoperative management of AA patients and therefore to further improve their prognosis.

Compared with most other studies, the baseline characteristics and comorbidities of AA patients in our study were broadly similar, including an advanced age, predominantly males, and a higher prevalence of hypertension comorbidity. For example, in a cohort from Japan who underwent open or endovascular repair for $A A A^{20}$, only $1.4 \%$ (14/999) patients aged 50 years or younger, $85.3 \%$ (852/999) were male, and $79.9 \%$ (798/999) had hypertension. In a retrospective cross-sectional study from Iran ${ }^{21}$, the mean age of AAA patients in emergency department was $68.11 \pm 11.98$ years, $84 \%$ were male, and $51.6 \%$ had hypertension. In a cohort of 107 untreated TAA patients ${ }^{22}$, the average age was 59.3 years, $73.8 \%$ $(79 / 107)$ patients were male, and $47 \%$ had diastolic hypertension. Similarities between these studies might be related to the nature of the diseases, but it should be noticed that in our study the study population were only AA patients who survived after the surgery therapy and needed an admission to ICU. This might explain the slight difference in these characteristics between studies. A recent study found that female AAA patients might have higher risk of rupture due to gender differences in morphological and hemodynamic characteristics of $A A A^{23}$, and considering that patients with rupture were more likely to be admitted to ICU after surgery ${ }^{17}$, our study thus included more female AAA patients. However, given the limited sample size of all these studies, variations in statistics of these characteristics could also explain the difference. In terms of ethnicity, most patients were Caucasian in our study, which was consistent with several other studies ${ }^{24-26}$ that supported Caucasian race might be a risk factor for development of AAA. Researches that compared AAA with TAA were rare, making it impossible to compare our results with others. In our study, the TAA patients were younger, with a much lower proportion of rupture, and different patterns of comorbidities when compared with AAA patients. These differences might be related to the "selection bias" of our study population. As mentioned above, only patients who underwent a surgery, survived, and at the same time needed to be admitted to ICU would be included into our study. Considering TAA had worse prognosis ${ }^{27}$, it is not strange to find that patients who survived and therefore 
were enrolled were younger and presented a different pattern of comorbidities compared with the AAA patients who were much elder.

Reports about prognosis of AA patients varied. A study included 138 ruptured AAA patients who received open surgical repair and survived at least 48 hours in ICU between 1999 and 2003 reported a 30-day mortality of $22 \%{ }^{28}$. This mortality rate was much higher than that of our study population, which might be related to the different study population since ruptured AA had significantly higher risk of mortality. In our study we also found that compared with patients without ruptured AA, the risk of ICU mortality of patients with ruptured AA increased (OR 3.31,95\% Cl 1.53-7.18). Another reason could be the different surgery therapies used, since EVAR was found to have lower perioperative mortality than open surgery ${ }^{29}$. Although in our study detailed information about surgery therapy was unavailable, given the study period was between 2014 and 2015, and most cases received elective surgery, they might be less likely to receive open surgery. We also found that patients with longer length of ICU stay had worse prognosis, which was consistent with the study conducted by Gavali et $\mathrm{al}^{30}$.

Among the many variables, only a few factors that related to the condition itself were significantly associated with prognosis, including elective surgery, rupture of $A A$, and type of $A A$, while none of the comorbidities show a significant association. These results suggested at least the short-term prognosis was mainly determined by the condition itself. APACHE IVa was also found to be associated with ICU mortality of the study population, and ROC curve analysis showed it had good discriminatory capability. This is consistent with Kabbani et $\mathrm{al}^{31}$ study where they found APACHE III score on ICU admission was an excellent discriminator of hospital mortality (AUC $0.92,95 \% \mathrm{Cl} 0.83-1.00$ ) for patients after open thoracoabdominal and open AAA repair. As far as know, there is no study evaluate the predictive performance of APACHE IVa in AAA and TAA patients after surgery therapy, and thus our finding could be seen as a validation of this scoring system in AA patients.

\section{Strengths and Limitations}

Strengths of the study included a multiple centers design and the updated data. The relatively large sample size also increased the power of the study. In addition, benefiting from the great abundance of variables in the database, various variables about baseline characteristics and comorbidities were investigated in the study. However, the study inevitably had some limitations. First, as a retrospective study, all the data we used were directly extracted from the available database without validation, and therefore measurement error should be considered as the main source of bias in the study. For example, it is possible that a diagnosis of AAA, TAA, or a TAA that also involves the aortic valve could be entered into the database incorrectly, since it was usually entered by nurses instead of clinicians. Second, since the database only contained data during the ICU hospitalization, information about surgery therapy before ICU was unavailable. We therefore applied strict inclusion criteria on the study population, and only included patients who were with a primary diagnosis of AAA or TAA and were directly admitted to ICU from operating room, recovery room, or PACU. Another concern was potential selection bias of the study population. Since not every ICU or hospital participated in the eICU program, AA patients admitted to 
those unanticipated ICU/hospitals would always be missed in our study. Nevertheless, further studies are needed to validate the findings in our study.

\section{Conclusion}

Prognosis of aortic aneurysm patients admitted to ICU postoperatively is yet to improve, and factors associated with prognosis are mainly related to the condition itself, while APACHE IVa is a reliable tool for prognosis prediction.

\section{References}

1. Creager MA, Belkin M, Bluth El, et al. 2012 ACCF/AHA/ACR/SCAI/SIR/STS/SVM/SVN/SVS Key data elements and definitions for peripheral atherosclerotic vascular disease: a report of the American College of Cardiology Foundation/American Heart Association Task Force on Clinical Data Standards (Writing Committee to develop Clinical Data Standards for peripheral atherosclerotic vascular disease). J Am Coll Cardiol. Jan 17 2012;59(3):294-357. doi:10.1016/j.jacc.2011.10.860

2. Hiratzka LF, Bakris GL, Beckman JA, et al. 2010 ACCF/AHA/AATS/ACR/ASA/SCA/SCAI/SIR/STS/SVM guidelines for the diagnosis and management of patients with Thoracic Aortic Disease: a report of the American College of Cardiology Foundation/American Heart Association Task Force on Practice Guidelines, American Association for Thoracic Surgery, American College of Radiology, American Stroke Association, Society of Cardiovascular Anesthesiologists, Society for Cardiovascular Angiography and Interventions, Society of Interventional Radiology, Society of Thoracic Surgeons, and Society for Vascular Medicine. Circulation. Apr 6 2010;121(13):e266-369. doi:10.1161/CIR.0b013e3181d4739e

3. Johnston KW, Rutherford RB, Tilson MD, Shah DM, Hollier L, Stanley JC. Suggested standards for reporting on arterial aneurysms. Subcommittee on Reporting Standards for Arterial Aneurysms, Ad Hoc Committee on Reporting Standards, Society for Vascular Surgery and North American Chapter, International Society for Cardiovascular Surgery. J Vasc Surg. Mar 1991;13(3):452-8. doi:10.1067/mva.1991.26737

4. Kent KC. Clinical practice. Abdominal aortic aneurysms. N Engl J Med. Nov 27 2014;371(22):2101-8. doi:10.1056/NEJMcp1401430

5. Ashton HA, Buxton MJ, Day NE, et al. The Multicentre Aneurysm Screening Study (MASS) into the effect of abdominal aortic aneurysm screening on mortality in men: a randomised controlled trial. Lancet. Nov 16 2002;360(9345):1531-9. doi:10.1016/s0140-6736(02)11522-4

6. Norman PE, Jamrozik K, Lawrence-Brown MM, et al. Population based randomised controlled trial on impact of screening on mortality from abdominal aortic aneurysm. BMJ. Nov 27 2004;329(7477):1259. doi:10.1136/bmj.38272.478438.55

7. Lindholt JS, Juul S, Fasting H, Henneberg EW. Screening for abdominal aortic aneurysms: single centre randomised controlled trial. BMJ. Apr 2 2005;330(7494):750. 
doi:10.1136/bmj.38369.620162.82

8. Ashton HA, Gao L, Kim LG, Druce PS, Thompson SG, Scott RA. Fifteen-year follow-up of a randomized clinical trial of ultrasonographic screening for abdominal aortic aneurysms. Br J Surg. Jun 2007;94(6):696-701. doi:10.1002/bjs.5780

9. Itani Y, Watanabe S, Masuda Y, et al. Measurement of aortic diameters and detection of asymptomatic aortic aneurysms in a mass screening program using a mobile helical computed tomography unit. Heart Vessels. Jan 2002;16(2):42-5. doi:10.1007/s380-002-8315-1

10. Kalsch H, Lehmann N, Mohlenkamp S, et al. Body-surface adjusted aortic reference diameters for improved identification of patients with thoracic aortic aneurysms: results from the population-based Heinz Nixdorf Recall study. Int J Cardiol. Feb 10 2013;163(1):72-8. doi:10.1016/j.ijcard.2011.05.039

11. Swerdlow NJ, Wu WW, Schermerhorn ML. Open and Endovascular Management of Aortic Aneurysms. Circ Res. Feb 15 2019;124(4):647-661. doi:10.1161/CIRCRESAHA.118.313186

12. Brady AR, Fowkes FG, Greenhalgh RM, Powell JT, Ruckley CV, Thompson SG. Risk factors for postoperative death following elective surgical repair of abdominal aortic aneurysm: results from the UK Small Aneurysm Trial. On behalf of the UK Small Aneurysm Trial participants. Br J Surg. Jun 2000;87(6):742-9. doi:10.1046/j.1365-2168.2000.01410.x

13. Dillavou ED, Muluk SC, Makaroun MS. Improving aneurysm-related outcomes: nationwide benefits of endovascular repair. J Vasc Surg. Mar 2006;43(3):446-51; discussion 451-2. doi:10.1016/j.jvs.2005.11.017

14. Lee WA, Carter JW, Upchurch G, Seeger JM, Huber TS. Perioperative outcomes after open and endovascular repair of intact abdominal aortic aneurysms in the United States during 2001. J Vasc Surg. Mar 2004;39(3):491-6. doi:10.1016/j.jvs.2003.12.001

15. Lieberg J, Pruks LL, Kals M, Paapstel K, Aavik A, Kals J. Mortality After Elective and Ruptured Abdominal Aortic Aneurysm Surgical Repair: 12-Year Single-Center Experience of Estonia. Scand J Surg. Jun 2018;107(2):152-157. doi:10.1177/1457496917738923

16. Kuckelman J, Niven A, Martin MJ. Postoperative Intensive Care Unit Management After Ruptured Abdominal Aortic Aneurysm. In: Starnes BW, Mehta M, Veith FJ, eds. Ruptured Abdominal Aortic Aneurysm: The Definitive Manual. Springer International Publishing; 2017:273-310.

17. Lawlor DK, Lovell MB, DeRose G, Forbes TL, Harris KA. Is intensive care necessary after elective abdominal aortic aneurysm repair? Can J Surg. Oct 2004;47(5):359-63.

18. Bisgaard J, Jørgensen HK, Gilsaa T, Ronholm E, Toft P. Aortic aneurysm disease versus aortic occlusive disease: differences in postoperative ICU requirements after open elective abdominal aortic surgery. Critical Care. 2012/03/20 2012;16(1):P470. doi:10.1186/cc11077

19. Pollard TJ, Johnson AEW, Raffa JD, Celi LA, Mark RG, Badawi O. The elCU Collaborative Research Database, a freely available multi-center database for critical care research. Sci Data. Sep 11 2018;5:180178. doi:10.1038/sdata.2018.178

20. Nakano M, Kimura N, Matsumoto H, et al. Characteristics of Abdominal Aortic Aneurysm in Japanese Patients Aged 50 Years or Younger. Ann Vasc Dis. Jun 25 2017;10(2):119-124. 
doi:10.3400/avd.oa.16-00083

21. Forouzanfar MM, Barazesh F, Hashemi B, Safari S. Characteristics and Outcome of Abdominal Aortic Aneurysm in Emregncy Department; a 10-year Cross-sectional Study. Arch Acad Emerg Med. 2020;8(1):e4.

22. Joyce JW, Fairbairn JF, 2nd, Kincaid OW, Juergen JL. Aneurysms of the Thoracic Aorta. A Clinical Study with Special Reference to Prognosis. Circulation. Feb 1964;29:176-81.

23. Gao Z, Xiong J, Chen Z, et al. Gender differences of morphological and hemodynamic characteristics of abdominal aortic aneurysm. Biol Sex Differ. Jul 21 2020;11(1):41. doi:10.1186/s13293-02000318-3

24. Salem MK, Rayt HS, Hussey G, et al. Should Asian men be included in abdominal aortic aneurysm screening programmes? Eur J Vasc Endovasc Surg. Dec 2009;38(6):748-9.

doi:10.1016/j.ejvs.2009.07.012

25. Lederle FA, Johnson GR, Wilson SE, et al. The aneurysm detection and management study screening program: validation cohort and final results. Aneurysm Detection and Management Veterans Affairs Cooperative Study Investigators. Arch Intern Med. May 22 2000;160(10):1425-30. doi:10.1001/archinte.160.10.1425

26. Kent KC, Zwolak RM, Egorova NN, et al. Analysis of risk factors for abdominal aortic aneurysm in a cohort of more than 3 million individuals. J Vasc Surg. Sep 2010;52(3):539-48. doi:10.1016/j.jvs.2010.05.090

27. Jonker $\mathrm{FH}$, Verhagen $\mathrm{HJ}$, Lin $\mathrm{PH}$, et al. Outcomes of endovascular repair of ruptured descending thoracic aortic aneurysms. Circulation. Jun 29 2010;121(25):2718-23.

doi:10.1161/CIRCULATIONAHA.109.908871

28. Laukontaus SJ, Lepantalo M, Hynninen M, Kantonen I, Pettila V. Prediction of survival after 48-h of intensive care following open surgical repair of ruptured abdominal aortic aneurysm. Eur J Vasc Endovasc Surg. Nov 2005;30(5):509-15. doi:10.1016/j.ejvs.2005.06.013

29. Giles KA, Pomposelli F, Hamdan A, Wyers M, Jhaveri A, Schermerhorn ML. Decrease in total aneurysm-related deaths in the era of endovascular aneurysm repair. J Vasc Surg. Mar 2009;49(3):543-50; discussion 550-1. doi:10.1016/j.jvs.2008.09.067

30. Gavali H, Mani K, Tegler G, Kawati R, Covaciu L, Wanhainen A. Editor's Choice - Prolonged ICU Length of Stay after AAA Repair: Analysis of Time Trends and Long-term Outcome. Eur J Vasc Endovasc Surg. Aug 2017;54(2):157-163. doi:10.1016/j.ejvs.2017.05.014

31. Kabbani LS, Escobar GA, Knipp B, et al. APACHE III score on ICU admission predicts hospital mortality after open thoracoabdominal and open abdominal aortic aneurysm repair. Ann Vasc Surg. Nov 2010;24(8):1060-7. doi:10.1016/j.avsg.2010.07.011

\section{Tables}

Table 1 Baseline characteristics of the study population 


\begin{tabular}{|c|c|c|c|c|}
\hline Variables & $\begin{array}{l}\text { All patients } \\
(n=974)\end{array}$ & $\begin{array}{l}\text { Abdominal aortic } \\
\text { aneurysm } \\
(n=677)\end{array}$ & $\begin{array}{l}\text { Thoracic aortic } \\
\text { aneurysm } \\
(n=297)\end{array}$ & $\begin{array}{l}P \\
\text { value }\end{array}$ \\
\hline Age (years) & 70 (62-77) & 72 (65-78) & 64 (54-74) & $<0.001$ \\
\hline Male & 726 (74.54\%) & $536(79.17 \%)$ & $190(63.97 \%)$ & $<0.001$ \\
\hline Ethnicity & & & & $<0.001$ \\
\hline Caucasian & 801 (82.24\%) & 577 (85.23\%) & $224(75.42 \%)$ & \\
\hline African American & $96(9.86 \%)$ & 47 (6.94\%) & $49(16.50 \%)$ & \\
\hline Asian & $12(1.23 \%)$ & $7(1.03 \%)$ & $5(1.68 \%)$ & \\
\hline Hispanic & $12(1.23 \%)$ & $10(1.48 \%)$ & $2(0.67 \%)$ & \\
\hline Native American & $3(0.31 \%)$ & $0(0.00 \%)$ & $3(1.01 \%)$ & \\
\hline Other/Unknown & $50(5.13 \%)$ & $36(5.32 \%)$ & $14(4.71 \%)$ & \\
\hline BMI $\left(\mathrm{kg} / \mathrm{m}^{2}\right)$ & $\begin{array}{l}27.59(24.22- \\
31.46)\end{array}$ & $\begin{array}{l}27.46(24.20- \\
31.10)\end{array}$ & $\begin{array}{l}28.04(24.28- \\
32.92)\end{array}$ & 0.129 \\
\hline $\begin{array}{l}\text { Year of the hospital } \\
\text { discharge date }\end{array}$ & & & & 0.887 \\
\hline 2014 & 482 (49.49\%) & 334 (49.34\%) & $148(49.83 \%)$ & \\
\hline 2015 & $492(50.51 \%)$ & 343 (50.66\%) & 149 (50.17\%) & \\
\hline Elective surgery & 854 (87.68\%) & 603 (89.07\%) & 251 (84.51\%) & 0.046 \\
\hline $\begin{array}{l}\text { Rupture of aortic } \\
\text { aneurysm }\end{array}$ & $76(7.80 \%)$ & 69 (10.19\%) & 7 (2.36\%) & $<0.001$ \\
\hline Type of ICU & & & & $<0.001$ \\
\hline Med-Surg ICU & 287 (29.47\%) & 232 (34.27\%) & 55 (18.52\%) & \\
\hline CSICU & $154(15.81 \%)$ & 115 (16.99\%) & $39(13.13 \%)$ & \\
\hline CTICU & $184(18.89 \%)$ & 87 (12.85\%) & 97 (32.66\%) & \\
\hline CCU-CTICU & 169 (17.35\%) & 95 (14.03\%) & 74 (24.92\%) & \\
\hline SICU & $124(12.73 \%)$ & $97(14.33 \%)$ & 27 (9.09\%) & \\
\hline Cardiac ICU & 30 (3.08\%) & 27 (3.99\%) & $3(1.01 \%)$ & \\
\hline Neuro ICU & $20(2.05 \%)$ & $18(2.66 \%)$ & $2(0.67 \%)$ & \\
\hline MICU & $6(0.62 \%)$ & $6(0.89 \%)$ & $0(0.00 \%)$ & \\
\hline Location admitted from & & & & 0.079 \\
\hline
\end{tabular}




\begin{tabular}{|c|c|c|c|c|}
\hline Operating Room & 767 (78.75\%) & $523(77.25 \%)$ & $244(82.15 \%)$ & \\
\hline Recovery Room & 169 (17.35\%) & $122(18.02 \%)$ & 47 (15.82\%) & \\
\hline PACU & $38(3.90 \%)$ & $32(4.73 \%)$ & $6(2.02 \%)$ & \\
\hline $\begin{array}{l}\text { Acute physiology IVa } \\
\text { score }\end{array}$ & $32(24-47.75)$ & $30(22-42)$ & $41(29-61)$ & $<0.001$ \\
\hline APACHE IVa score & $47(37-62)$ & $45(36-57)$ & $52(37.25-75)$ & $<0.001$ \\
\hline \multicolumn{5}{|l|}{$\begin{array}{l}\text { Lab variables in } \\
\text { APACHE IVa score }\end{array}$} \\
\hline Temperature $\left({ }^{\circ} \mathrm{C}\right)$ & $36.3(35.8-36.6)$ & $36.3(36.0-36.6)$ & $36.1(35.5-36.6)$ & $<0.001$ \\
\hline $\begin{array}{l}\text { Mean blood pressure } \\
(\mathrm{mmHg})\end{array}$ & $68(56-132)$ & $71(57-133)$ & $62(52-128)$ & $<0.001$ \\
\hline Heart rate $(/ \mathrm{min})$ & $96(59-109)$ & $96(58-108)$ & $99(82-112)$ & 0.006 \\
\hline Respiratory rate (/min) & $13(9-31)$ & $14(9-32)$ & $12(8-30)$ & 0.004 \\
\hline $\mathrm{FiO}_{2}(\%)$ & $50(40-80)$ & $50(40-80)$ & $60(40-87.50)$ & 0.087 \\
\hline $\mathrm{PaO}_{2}(\mathrm{mmHg})$ & $\begin{array}{l}102.90(80.00- \\
154.45)\end{array}$ & $\begin{array}{l}103.00(80.00- \\
159.00)\end{array}$ & $\begin{array}{l}101.65(79.00- \\
151.00)\end{array}$ & 0.553 \\
\hline $\mathrm{PaCO}_{2}(\mathrm{mmHg})$ & $\begin{array}{l}42.00(37.00- \\
46.25)\end{array}$ & $\begin{array}{l}42.00(37.00- \\
46.10)\end{array}$ & $\begin{array}{l}42.00(37.38- \\
46.77)\end{array}$ & 0.875 \\
\hline Arterial pH & $7.36(7.31-7.40)$ & $7.34(7.30-7.39)$ & 7.37 (7.33-7.41) & 0.002 \\
\hline Sodium (mEq/L) & $139(136-141)$ & $139(136-141)$ & $140(138-143.5)$ & $<0.001$ \\
\hline Urine output (mL/24h) & $\begin{array}{l}1621.99(987.60- \\
2586.69)\end{array}$ & $\begin{array}{l}1585.01(907.72- \\
2472.42)\end{array}$ & $\begin{array}{l}\text { 1691.02 (1172.02- } \\
2791.11)\end{array}$ & 0.096 \\
\hline Creatinine (mg/dL) & $1.00(0.80-1.40)$ & $1.00(0.80-1.36)$ & $1.02(0.75-1.50)$ & 0.888 \\
\hline $\begin{array}{l}\text { Blood urea nitrogen } \\
(\mathrm{mg} / \mathrm{dL})\end{array}$ & $17(13-23)$ & $16.5(13-22)$ & $17(13-24.5)$ & 0.171 \\
\hline Glucose (mg/dL) & $141(105-182)$ & 138 (107.25-180) & 151 (99-184.5) & 0.564 \\
\hline Albumin (g/dL) & $2.90(2.50-3.30)$ & $2.90(2.50-3.30)$ & $2.90(2.48-3.30)$ & 0.930 \\
\hline Bilirubin (mg/dL) & $0.90(0.50-1.55)$ & $0.80(0.50-1.33)$ & $1.10(0.60-1.90)$ & 0.008 \\
\hline Hematocrit (\%) & $\begin{array}{l}31.50(27.40- \\
35.60)\end{array}$ & $\begin{array}{l}32.55(28.83- \\
36.50)\end{array}$ & $\begin{array}{l}29.10(25.50- \\
33.20)\end{array}$ & $<0.001$ \\
\hline WBC $\left(x 1000 / \mathrm{mm}^{3}\right)$ & $\begin{array}{l}10.50(7.98- \\
14.70)\end{array}$ & $10.30(7.90-14.10)$ & $12.20(8.20-16.60)$ & 0.003 \\
\hline Intubated & $255(26.18 \%)$ & $120(17.73 \%)$ & 135 (45.45\%) & $<0.001$ \\
\hline Ventilation & $269(27.62 \%)$ & $138(20.38 \%)$ & $131(44.11 \%)$ & $<0.001$ \\
\hline
\end{tabular}


Note: $P$ value $<0.05$ was presented in bold.

Abbreviations: BMI, body mass index; ICU, intensive care unit; Med-Surg ICU, medical-surgical intensive care unit; CSICU, cardiac surgery intensive care unit; CTICU, cardiothoracic intensive care unit; CCU-CTICU, coronary care unit-cardiothoracic intensive care unit; SICU, surgical intensive care unit; MICU, medical intensive care unit; PACU, post anesthesia care unit; APACHE, Acute Physiology And Chronic Health Evaluation; $\mathrm{FiO}_{2}$, fraction of inspired oxygen; $\mathrm{PaO}_{2}$, partial pressure of oxygen; $\mathrm{PaCO}_{2}$, partial pressure of carbon dioxide; WBC, white blood cell.

Table 2 Comorbidities of the study population 


\begin{tabular}{|c|c|c|c|c|}
\hline Variables & $\begin{array}{l}\text { All } \\
\text { patients } \\
(n=974)\end{array}$ & $\begin{array}{l}\text { Abdominal aortic } \\
\text { aneurysm } \\
(n=677)\end{array}$ & $\begin{array}{l}\text { Thoracic aortic } \\
\text { aneurysm } \\
(n=297)\end{array}$ & $\begin{array}{l}\mathrm{P} \\
\text { value }\end{array}$ \\
\hline $\begin{array}{l}\text { History of coronary artery bypass } \\
\text { surgery }\end{array}$ & $\begin{array}{l}87 \\
(8.93 \%)\end{array}$ & $72(10.64 \%)$ & $15(5.05 \%)$ & 0.005 \\
\hline History of angina & $\begin{array}{l}24 \\
(2.46 \%)\end{array}$ & $20(2.95 \%)$ & $4(1.35 \%)$ & 0.179 \\
\hline History of myocardial infarction & $\begin{array}{l}96 \\
(9.86 \%)\end{array}$ & $80(11.82 \%)$ & $16(5.39 \%)$ & 0.002 \\
\hline $\begin{array}{l}\text { History of percutaneous coronary } \\
\text { intervention }\end{array}$ & $\begin{array}{l}63 \\
(6.47 \%)\end{array}$ & $51(7.53 \%)$ & $12(4.04 \%)$ & 0.041 \\
\hline $\begin{array}{l}\text { History of congestive heart } \\
\text { failure }\end{array}$ & $\begin{array}{l}66 \\
(6.78 \%)\end{array}$ & $36(5.32 \%)$ & $30(10.10 \%)$ & 0.006 \\
\hline History of atrial fibrillation & $\begin{array}{l}80 \\
(8.21 \%)\end{array}$ & $56(8.27 \%)$ & $24(8.08 \%)$ & 0.920 \\
\hline History of AICD/pacemaker & $\begin{array}{l}25 \\
(2.57 \%)\end{array}$ & $16(2.36 \%)$ & $9(3.03 \%)$ & 0.518 \\
\hline $\begin{array}{l}\text { History of hypertension requiring } \\
\text { treatment }\end{array}$ & $\begin{array}{l}572 \\
(58.73 \%)\end{array}$ & $388(57.31 \%)$ & $184(61.95 \%)$ & 0.176 \\
\hline History of heart valve disease & $\begin{array}{l}71 \\
(7.29 \%)\end{array}$ & $27(3.99 \%)$ & $44(14.81 \%)$ & $<0.001$ \\
\hline History of COPD & $\begin{array}{l}125 \\
(12.83 \%)\end{array}$ & $99(14.62 \%)$ & $26(8.75 \%)$ & 0.012 \\
\hline History of asthma & $\begin{array}{l}35 \\
(3.59 \%)\end{array}$ & $20(2.95 \%)$ & 15 (5.05\%) & 0.106 \\
\hline History of respiratory failure & $\begin{array}{l}5 \\
(0.51 \%)\end{array}$ & $4(0.59 \%)$ & $1(0.34 \%)$ & 1.000 \\
\hline $\begin{array}{l}\text { History of restrictive pulmonary } \\
\text { disease }\end{array}$ & $\begin{array}{l}7 \\
(0.72 \%)\end{array}$ & $4(0.59 \%)$ & $3(1.01 \%)$ & 0.442 \\
\hline History of cirrhosis & $\begin{array}{l}16 \\
(1.64 \%)\end{array}$ & $13(1.92 \%)$ & $3(1.01 \%)$ & 0.416 \\
\hline History of peptic ulcer disease & $\begin{array}{l}22 \\
(2.26 \%)\end{array}$ & $17(2.51 \%)$ & $5(1.68 \%)$ & 0.492 \\
\hline History of renal insufficiency & $\begin{array}{l}86 \\
(8.83 \%)\end{array}$ & $53(7.83 \%)$ & $33(11.11 \%)$ & 0.096 \\
\hline History of dialysis & $\begin{array}{l}8 \\
(0.82 \%)\end{array}$ & $5(0.74 \%)$ & $3(1.01 \%)$ & 0.705 \\
\hline $\begin{array}{l}\text { History of non-cancerous } \\
\text { hematology disease }\end{array}$ & $\begin{array}{l}5 \\
(0.51 \%)\end{array}$ & $4(0.59 \%)$ & $1(0.34 \%)$ & 1.000 \\
\hline
\end{tabular}




\begin{tabular}{|c|c|c|c|c|}
\hline History of anemia & $\begin{array}{l}3 \\
(0.31 \%)\end{array}$ & $2(0.30 \%)$ & $1(0.34 \%)$ & 1.000 \\
\hline History of ITP & $\begin{array}{l}1 \\
(0.10 \%)\end{array}$ & $1(0.15 \%)$ & $0(0.00 \%)$ & 1.000 \\
\hline $\begin{array}{l}\text { History of peripheral vascular } \\
\text { disease }\end{array}$ & $\begin{array}{l}88 \\
(9.03 \%)\end{array}$ & $72(10.64 \%)$ & $16(5.39 \%)$ & 0.009 \\
\hline History of VTE & $\begin{array}{l}40 \\
(4.11 \%)\end{array}$ & $24(3.55 \%)$ & $16(5.39 \%)$ & 0.182 \\
\hline History of DVT & $\begin{array}{l}26 \\
(2.67 \%)\end{array}$ & $18(2.66 \%)$ & $8(2.69 \%)$ & 1.000 \\
\hline History of PE & $\begin{array}{l}18 \\
(1.85 \%)\end{array}$ & $10(1.48 \%)$ & $8(2.69 \%)$ & 0.203 \\
\hline History of diabetes & $\begin{array}{l}140 \\
(14.37 \%)\end{array}$ & $109(16.10 \%)$ & $31(10.44 \%)$ & 0.020 \\
\hline History of hyperthyroidism & $\begin{array}{l}6 \\
(0.62 \%)\end{array}$ & $4(0.59 \%)$ & $2(0.67 \%)$ & 1.000 \\
\hline History of hypothyroidism & $\begin{array}{l}68 \\
(6.98 \%)\end{array}$ & $43(6.35 \%)$ & $25(8.42 \%)$ & 0.244 \\
\hline History of stroke & $\begin{array}{l}57 \\
(5.85 \%)\end{array}$ & $37(5.47 \%)$ & $20(6.73 \%)$ & 0.437 \\
\hline History of TIA & $\begin{array}{l}34 \\
(3.49 \%)\end{array}$ & $23(3.40 \%)$ & $11(3.70 \%)$ & 0.810 \\
\hline History of dementia & $\begin{array}{l}3 \\
(0.31 \%)\end{array}$ & $3(0.44 \%)$ & $0(0.00 \%)$ & 0.557 \\
\hline $\begin{array}{l}\text { History of neuromuscular } \\
\text { disease }\end{array}$ & $\begin{array}{l}1 \\
(0.10 \%)\end{array}$ & $1(0.15 \%)$ & $0(0.00 \%)$ & 1.000 \\
\hline History of seizures & $\begin{array}{l}19 \\
(1.95 \%)\end{array}$ & $12(1.77 \%)$ & $7(2.36 \%)$ & 0.616 \\
\hline AIDS & $\begin{array}{l}4 \\
(0.41 \%)\end{array}$ & $3(0.44 \%)$ & $1(0.34 \%)$ & 1.000 \\
\hline $\begin{array}{l}\text { Immunosuppression within past } \\
6 \text { months }\end{array}$ & $\begin{array}{l}4 \\
(0.41 \%)\end{array}$ & $3(0.44 \%)$ & $1(0.34 \%)$ & 1.000 \\
\hline History of rheumatic disease & $\begin{array}{l}13 \\
(1.33 \%)\end{array}$ & $11(1.62 \%)$ & $2(0.67 \%)$ & 0.364 \\
\hline History of rheumatoid arthritis & $\begin{array}{l}13 \\
(1.33 \%)\end{array}$ & $11(1.62 \%)$ & $2(0.67 \%)$ & 0.364 \\
\hline History of SLE & $\begin{array}{l}1 \\
(0.10 \%)\end{array}$ & $1(0.15 \%)$ & $0(0.00 \%)$ & 1.000 \\
\hline History of heart transplant & $\begin{array}{l}2 \\
(0.21 \%)\end{array}$ & $2(0.30 \%)$ & $0(0.00 \%)$ & 1.000 \\
\hline
\end{tabular}




\begin{tabular}{|c|c|c|c|c|}
\hline History of liver transplant & $\begin{array}{l}1 \\
(0.10 \%)\end{array}$ & $1(0.15 \%)$ & $0(0.00 \%)$ & 1.000 \\
\hline History of renal transplant & $\begin{array}{l}4 \\
(0.41 \%)\end{array}$ & $2(0.30 \%)$ & $2(0.67 \%)$ & 0.590 \\
\hline History of cancer & $\begin{array}{l}116 \\
(11.91 \%)\end{array}$ & $88(13.00 \%)$ & $28(9.43 \%)$ & 0.113 \\
\hline History of metastases cancer & $\begin{array}{l}4 \\
(0.41 \%)\end{array}$ & $2(0.30 \%)$ & $2(0.67 \%)$ & 0.590 \\
\hline History of head neck cancer & $\begin{array}{l}6 \\
(0.62 \%)\end{array}$ & $6(0.89 \%)$ & $0(0.00 \%)$ & 0.186 \\
\hline History of esophagus cancer & $\begin{array}{l}4 \\
(0.41 \%)\end{array}$ & $4(0.59 \%)$ & $0(0.00 \%)$ & 0.320 \\
\hline History of lung cancer & $\begin{array}{l}16 \\
(1.64 \%)\end{array}$ & $14(2.07 \%)$ & $2(0.67 \%)$ & 0.170 \\
\hline History of breast cancer & $\begin{array}{l}12 \\
(1.23 \%)\end{array}$ & $6(0.89 \%)$ & $6(2.02 \%)$ & 0.203 \\
\hline History of liver cancer & $\begin{array}{l}2 \\
(0.21 \%)\end{array}$ & $1(0.15 \%)$ & $1(0.34 \%)$ & 0.517 \\
\hline History of stomach cancer & $\begin{array}{l}3 \\
(0.31 \%)\end{array}$ & $2(0.30 \%)$ & $1(0.34 \%)$ & 1.000 \\
\hline History of bladder cancer & $\begin{array}{l}10 \\
(1.03 \%)\end{array}$ & $9(1.33 \%)$ & $1(0.34 \%)$ & 0.298 \\
\hline History of kidney cancer & $\begin{array}{l}10 \\
(1.03 \%)\end{array}$ & $5(0.74 \%)$ & $5(1.68 \%)$ & 0.183 \\
\hline History of colon cancer & $\begin{array}{l}5 \\
(0.51 \%)\end{array}$ & $5(0.74 \%)$ & $0(0.00 \%)$ & 0.331 \\
\hline History of melanoma & $\begin{array}{l}8 \\
(0.82 \%)\end{array}$ & $6(0.89 \%)$ & $2(0.67 \%)$ & 1.000 \\
\hline History of ovary cancer & $\begin{array}{l}2 \\
(0.21 \%)\end{array}$ & $1(0.15 \%)$ & $1(0.34 \%)$ & 0.517 \\
\hline History of uterus cancer & $\begin{array}{l}1 \\
(0.10 \%)\end{array}$ & $1(0.15 \%)$ & $0(0.00 \%)$ & 1.000 \\
\hline History of prostate cancer & $\begin{array}{l}22 \\
(2.26 \%)\end{array}$ & $17(2.51 \%)$ & $5(1.68 \%)$ & 0.492 \\
\hline History of chemotherapy & $\begin{array}{l}3 \\
(0.31 \%)\end{array}$ & $2(0.30 \%)$ & $1(0.34 \%)$ & 1.000 \\
\hline $\begin{array}{l}\text { Radiation therapy within past } 6 \\
\text { months }\end{array}$ & $\begin{array}{l}2 \\
(0.21 \%)\end{array}$ & $2(0.30 \%)$ & $0(0.00 \%)$ & 1.000 \\
\hline
\end{tabular}


Note: $P$ value $<0.05$ was presented in bold.

Abbreviations: AICD, automatic implantable cardioverter defibrillator; COPD, Chronic obstructive pulmonary disease; ITP, Immune thrombocytopenic purpura; VTE, Venous Thromboembolism; DVT, Deep vein thrombosis; PE, pulmonary embolism; TIA, Transient Ischemic Attack; AIDS, acquired immune deficiency syndrome; SLE, systemic lupus erythematosus.

Table 3 Clinical outcomes of the study population stratified by length of ICU stay

\begin{tabular}{|c|c|c|c|c|}
\hline Clinical outcomes & $\begin{array}{l}\text { All patients } \\
(\mathrm{n}=974)\end{array}$ & $\begin{array}{l}\text { Abdominal aortic } \\
\text { aneurysm } \\
(n=677)\end{array}$ & $\begin{array}{l}\text { Thoracic aortic } \\
\text { aneurysm } \\
(n=297)\end{array}$ & $\begin{array}{l}\mathrm{P} \\
\text { value }\end{array}$ \\
\hline ICU mortality & $44(4.52 \%)$ & $16(2.36 \%)$ & $28(9.43 \%)$ & $<0.001$ \\
\hline $\begin{array}{l}\text { Length of ICU stay <2 } \\
\text { days }\end{array}$ & $9(1.56 \%)$ & $5(1.08 \%)$ & $4(3.57 \%)$ & \\
\hline $\begin{array}{l}\text { Length of ICU stay 2-7 } \\
\text { days }\end{array}$ & $20(6.58 \%)$ & $5(3.07 \%)$ & $15(10.64 \%)$ & \\
\hline $\begin{array}{l}\text { Length of ICU stay } \geq 7 \\
\text { days }\end{array}$ & $15(15.96 \%)$ & $6(12.00 \%)$ & $9(20.45 \%)$ & \\
\hline$P$ value & $<0.001$ & $<0.001$ & 0.004 & \\
\hline Hospital mortality & $61(6.26 \%)$ & 25 (3.69\%) & $36(12.12 \%)$ & $<0.001$ \\
\hline $\begin{array}{l}\text { Length of ICU stay }<2 \\
\text { days }\end{array}$ & $12(2.08 \%)$ & $7(1.51 \%)$ & $5(4.46 \%)$ & \\
\hline $\begin{array}{l}\text { Length of ICU stay 2-7 } \\
\text { days }\end{array}$ & $29(9.54 \%)$ & $10(6.13 \%)$ & $19(13.48 \%)$ & \\
\hline $\begin{array}{l}\text { Length of ICU stay } \geq 7 \\
\text { days }\end{array}$ & $20(21.28 \%)$ & $8(16.00 \%)$ & $12(27.27 \%)$ & \\
\hline$P$ value & $<0.001$ & $<0.001$ & $<0.001$ & \\
\hline $\begin{array}{l}\text { Length of ICU stay } \\
\text { (days) }\end{array}$ & $\begin{array}{l}1.54(0.99- \\
3.24)\end{array}$ & $1.17(0.94-2.68)$ & $2.37(1.36-4.67)$ & $<0.001$ \\
\hline $\begin{array}{l}\text { Length of hospital stay } \\
\text { (days) }\end{array}$ & $\begin{array}{l}4.79(2.10- \\
8.33)\end{array}$ & $3.25(1.40-7.33)$ & $6.40(4.36-10.44)$ & $<0.001$ \\
\hline
\end{tabular}

Note: $P$ value $<0.05$ was presented in bold.

Abbreviations: ICU, intensive care unit.

Table 4 Univariable Cox regression analysis of baseline characteristics associated with ICU mortality 


\begin{tabular}{|c|c|c|c|}
\hline Variables & OR & $95 \% \mathrm{Cl}$ & $P$ value \\
\hline Age (years) & 0.98 & $0.95-1.00$ & 0.0356 \\
\hline \multicolumn{4}{|l|}{ Sex } \\
\hline Male & 1.0 & & \\
\hline Female & 1.55 & $0.82-2.94$ & 0.1818 \\
\hline \multicolumn{4}{|l|}{ Ethnicity } \\
\hline Caucasian & 1.0 & & \\
\hline African American & 1.28 & $0.49-3.36$ & 0.6177 \\
\hline Asian & 0.00 & $0.00-\operatorname{Inf}$ & 0.9845 \\
\hline Hispanic & 4.65 & $0.98-22.10$ & 0.0530 \\
\hline Native American & 46.55 & $4.12-526.41$ & 0.0019 \\
\hline Other/Unknown & 0.97 & $0.23-4.16$ & 0.9670 \\
\hline $\mathrm{BMI}\left(\mathrm{kg} / \mathrm{m}^{2}\right)$ & 0.99 & $0.95-1.04$ & 0.8133 \\
\hline \multicolumn{4}{|c|}{ Year of the hospital discharge date } \\
\hline 2014 & 1.0 & & \\
\hline 2015 & 1.08 & $0.59-1.97$ & 0.8112 \\
\hline \multicolumn{4}{|l|}{ Elective surgery } \\
\hline No & 1.0 & & \\
\hline Yes & 0.22 & $0.12-0.42$ & $<0.0001$ \\
\hline \multicolumn{4}{|c|}{ Rupture of aortic aneurysm } \\
\hline No & 1.0 & & \\
\hline Yes & 3.31 & $1.53-7.18$ & 0.0024 \\
\hline \multicolumn{4}{|l|}{ Type of ICU } \\
\hline Med-Surg ICU & 1.0 & & \\
\hline CSICU & 1.78 & $0.79-4.01$ & 0.1627 \\
\hline CTICU & 0.71 & $0.27-1.90$ & 0.4966 \\
\hline CCU-CTICU & 0.64 & $0.22-1.84$ & 0.4088 \\
\hline
\end{tabular}




\begin{tabular}{|c|c|c|c|}
\hline SICU & 1.26 & $0.49-3.24$ & 0.6302 \\
\hline Cardiac ICU & 0.00 & $0.00-\operatorname{lnf}$ & 0.9840 \\
\hline Neuro ICU & 1.11 & $0.14-8.94$ & 0.9224 \\
\hline MICU & 0.00 & $0.00-\operatorname{lnf}$ & 0.9928 \\
\hline \multicolumn{4}{|l|}{ Location admitted from for ICU } \\
\hline Operating Room & 1.0 & & \\
\hline Recovery Room & 0.57 & $0.22-1.47$ & 0.2430 \\
\hline PACU & 0.00 & $0.00-\operatorname{lnf}$ & 0.9818 \\
\hline \multicolumn{4}{|l|}{ Type of aortic aneurysm } \\
\hline Abdominal aortic aneurysm & 1.0 & & \\
\hline Thoracic aortic aneurysm & 4.30 & $2.29-8.08$ & $<0.0001$ \\
\hline \multicolumn{4}{|l|}{ Type of aortic aneurysm } \\
\hline Abdominal aortic aneurysm & 1.0 & & \\
\hline Abdominal aortic aneurysm with dissection & 4.15 & $1.04-16.49$ & 0.0434 \\
\hline Abdominal aortic aneurysm with rupture & 7.37 & $2.40-22.63$ & 0.0005 \\
\hline Thoracic aortic aneurysm & 4.19 & $1.57-11.15$ & 0.0042 \\
\hline Thoracic aortic aneurysm with dissection & 14.52 & $5.74-36.70$ & $<0.0001$ \\
\hline Thoracic aortic aneurysm with rupture & 58.07 & $10.91-309.22$ & $<0.0001$ \\
\hline Acute physiology score IVa & 1.05 & $1.04-1.06$ & $<0.0001$ \\
\hline APACHE IVa score & 1.05 & $1.04-1.06$ & $<0.0001$ \\
\hline \multicolumn{4}{|l|}{ Lab variables in APACHE IVa score } \\
\hline Temperature $\left({ }^{\circ} \mathrm{C}\right)$ & 0.58 & $0.47-0.72$ & $<0.0001$ \\
\hline Mean blood pressure $(\mathrm{mmHg})$ & 1.00 & $0.99-1.00$ & 0.2350 \\
\hline Heart rate $(/ \mathrm{min})$ & 1.03 & $1.02-1.04$ & $<0.0001$ \\
\hline Respiratory rate (/min) & 0.97 & $0.95-1.00$ & 0.0356 \\
\hline $\mathrm{FiO}_{2}(\%)$ & 1.03 & $1.02-1.05$ & $<0.0001$ \\
\hline \multirow[t]{2}{*}{$\mathrm{PaO}_{2}(\mathrm{mmHg})$} & 1.00 & $0.99-1.00$ & 0.6106 \\
\hline & 1.01 & $0.97-1.06$ & 0.6192 \\
\hline
\end{tabular}




\begin{tabular}{|c|c|c|c|}
\hline \multicolumn{4}{|l|}{$\mathrm{PaCO}_{2}(\mathrm{mmHg})$} \\
\hline Arterial pH & 0.00 & $0.00-0.00$ & $<0.0001$ \\
\hline Sodium (mEq/L) & 1.19 & $1.13-1.26$ & $<0.0001$ \\
\hline Urine output (mL/24h) & 1.00 & $1.00-1.00$ & 0.0021 \\
\hline Creatinine (mg/dL) & 1.75 & $1.39-2.20$ & $<0.0001$ \\
\hline Blood urea nitrogen (mg/dL) & 1.06 & $1.03-1.08$ & $<0.0001$ \\
\hline Glucose (mg/dL) & 1.01 & $1.00-1.01$ & 0.0005 \\
\hline Albumin (g/dL) & 0.22 & $0.11-0.44$ & $<0.0001$ \\
\hline Bilirubin (mg/dL) & 1.83 & $1.30-2.57$ & 0.0005 \\
\hline Hematocrit (\%) & 0.82 & $0.77-0.87$ & $<0.0001$ \\
\hline WBC $\left(x 1000 / \mathrm{mm}^{3}\right)$ & 1.05 & $1.00-1.09$ & 0.0284 \\
\hline \multicolumn{4}{|l|}{ Intubated } \\
\hline No & 1.0 & & \\
\hline Yes & 8.45 & $4.28-16.69$ & $<0.0001$ \\
\hline \multicolumn{4}{|l|}{ Ventilation } \\
\hline No & 1.0 & & \\
\hline Yes & 19.16 & $8.00-45.92$ & $<0.0001$ \\
\hline \multicolumn{4}{|l|}{ Dialysis } \\
\hline No & 1.0 & & \\
\hline Yes & 3.58 & $0.42-30.41$ & 0.2424 \\
\hline
\end{tabular}

Note: $P$ value $<0.05$ was presented in bold.

Abbreviations: ICU, intensive care unit; $\mathrm{OR}$, odds ratio; $\mathrm{Cl}$, confidence interval; $\mathrm{BMI}$, body mass index; MedSurg ICU, medical-surgical intensive care unit; CSICU, cardiac surgery intensive care unit; CTICU, cardiothoracic intensive care unit; CCU-CTICU, coronary care unit-cardiothoracic intensive care unit; SICU, surgical intensive care unit; MICU, medical intensive care unit; PACU, post anesthesia care unit; APACHE, Acute Physiology And Chronic Health Evaluation; $\mathrm{FiO}_{2}$, fraction of inspired oxygen; $\mathrm{PaO}_{2}$, partial pressure of oxygen; $\mathrm{PaCO}_{2}$, partial pressure of carbon dioxide; $\mathrm{WBC}$, white blood cell. 
Table 5 Univariable Cox regression analysis of comorbidities associated with ICU mortality 


\begin{tabular}{|c|c|c|c|}
\hline Variables & $\mathrm{OR}^{*}$ & $95 \% \mathrm{Cl}$ & $P$ value \\
\hline History of coronary artery bypass surgery & 0.23 & $0.03-1.68$ & 0.1467 \\
\hline History of angina & 0.92 & $0.12-6.95$ & 0.9332 \\
\hline History of myocardial infarction & 0.20 & $0.03-1.50$ & 0.1186 \\
\hline History of percutaneous coronary intervention & 0.33 & $0.04-2.40$ & 0.2712 \\
\hline History of congestive heart failure & 1.01 & $0.30-3.34$ & 0.9909 \\
\hline History of atrial fibrillation & 1.12 & $0.39-3.22$ & 0.8284 \\
\hline History of AICD/pacemaker & 0.00 & $0.00-\operatorname{Inf}$ & 0.9853 \\
\hline History of hypertension requiring treatment & 0.92 & $0.50-1.70$ & 0.7924 \\
\hline History of heart valve disease & 0.93 & $0.28-3.07$ & 0.9020 \\
\hline History of COPD & 0.87 & $0.33-2.24$ & 0.7656 \\
\hline History of asthma & 0.00 & $0.00-\operatorname{Inf}$ & 0.9826 \\
\hline History of respiratory failure & 0.00 & $0.00-\operatorname{lnf}$ & 0.9847 \\
\hline History of restrictive pulmonary disease & 3.58 & $0.42-30.41$ & 0.2424 \\
\hline History of cirrhosis & 1.42 & $0.18-10.99$ & 0.7378 \\
\hline History of peptic ulcer disease & 1.01 & $0.13-7.66$ & 0.9949 \\
\hline History of renal insufficiency & 1.68 & $0.69-4.09$ & 0.2551 \\
\hline History of dialysis & 3.07 & $0.37-25.48$ & 0.2997 \\
\hline History of non-cancerous hematology disease & 0.00 & $0.00-\operatorname{Inf}$ & 0.9847 \\
\hline History of anemia & 0.00 & $0.00-\operatorname{Inf}$ & 0.9881 \\
\hline History of ITP & 0.00 & $0.00-\operatorname{Inf}$ & 0.9896 \\
\hline History of peripheral vascular disease & 0.73 & $0.22-2.40$ & 0.6011 \\
\hline History of VTE & 0.53 & $0.07-3.96$ & 0.5371 \\
\hline History of DVT & 0.00 & $0.00-\operatorname{lnf}$ & 0.9850 \\
\hline History of PE & 1.25 & $0.16-9.60$ & 0.8308 \\
\hline History of diabetes & 0.58 & $0.21-1.66$ & 0.3122 \\
\hline History of hyperthyroidism & 4.30 & $0.49-37.63$ & 0.1873 \\
\hline History of hypothyroidism & 0.30 & $0.04-2.21$ & 0.2368 \\
\hline History of stroke & 1.19 & $0.36-3.96$ & 0.7802 \\
\hline
\end{tabular}




\begin{tabular}{|llll|}
\hline History of TIA & 1.34 & $0.31-5.76$ & 0.6975 \\
\hline History of dementia & 0.00 & $0.00-\operatorname{Inf}$ & 0.9881 \\
\hline History of neuromuscular disease & 0.00 & $0.00-\operatorname{Inf}$ & 0.9896 \\
\hline AlDS & 1.18 & $0.15-9.03$ & 0.8745 \\
\hline Immunosuppression within past 6 months & 0.00 & $0.00-\operatorname{Inf}$ & 0.9863 \\
\hline History of rheumatic disease & 7.19 & $0.73-70.52$ & 0.0905 \\
\hline History of rheumatoid arthritis & 1.78 & $0.23-14.00$ & 0.5841 \\
\hline History of SLE & 1.78 & $0.23-14.00$ & 0.5841 \\
\hline History of heart transplant & 0.00 & $0.00-\operatorname{Inf}$ & 0.9896 \\
\hline History of liver transplant & 0.00 & $0.00-\operatorname{Inf}$ & 0.9853 \\
\hline History of renal transplant & inf. & $0.00-\operatorname{Inf}$ & 0.9841 \\
\hline History of cancer & 7.19 & $0.73-70.52$ & 0.0905 \\
\hline History of metastases cancer & 0.16 & $0.02-1.21$ & 0.0761 \\
\hline History of head neck cancer & 0.00 & $0.00-\operatorname{Inf}$ & 0.9863 \\
\hline History of esophagus cancer & 0.00 & $0.00-\operatorname{Inf}$ & 0.9890 \\
\hline History of lung cancer & 0.00 & $0.00-\operatorname{Inf}$ & 0.9881 \\
\hline History of breast cancer & 0.00 & $0.00-\operatorname{Inf}$ & 0.9863 \\
\hline History of liver cancer & $0.00-\operatorname{Inf}$ & 0.9853 \\
\hline History of stomach cancer & 0.00 & $0.00-\operatorname{Inf}$ & 0.9820 \\
\hline History of bladder cancer & 0.00 & $0.00-\operatorname{Inf}$ & 0.9844 \\
\hline History of kidney cancer & 0.00 & $0.00-\operatorname{Inf}$ & 0.9853 \\
\hline History of colon cancer & $0.00-\operatorname{Inf}$ & 0.9881 \\
\hline History of melanoma & $0.00-\operatorname{Inf}$ & 0.9858 \\
\hline History of ovary cancer & $0.00-\operatorname{Inf}$ & 0.9873 \\
\hline History of uterus cancer & 0.9847 & 0.9853 \\
\hline History of prostate cancer & 0.9896 \\
\hline
\end{tabular}


Notes: * Compared with patients without the specific comorbidity; P value $<0.05$ was presented in bold.

Abbreviations: ICU, intensive care unit; OR, odds ratio; $\mathrm{Cl}$, confidence interval; $\mathrm{AICD}$, automatic implantable cardioverter defibrillator; COPD, Chronic obstructive pulmonary disease; ITP, Immune thrombocytopenic purpura; VTE, Venous Thromboembolism; DVT, Deep vein thrombosis; PE, pulmonary embolism; TIA, Transient Ischemic Attack; AIDS, acquired immune deficiency syndrome; SLE, systemic lupus erythematosus.

\section{Table 6 Predictive performance of APACHE IVa for ICU mortality}

\begin{tabular}{|llllll|}
\hline & AUC & $95 \% \mathrm{Cl}$ & Best threshold & Specificity & Sensitivity \\
\hline All patient & 0.9176 & $0.8789-0.9390$ & 58.5 & 0.7399 & 0.9767 \\
\hline Rupture of aortic aneurysm & & & & & \\
\hline No & 0.9158 & $0.8704-0.9419$ & 58.5 & 0.7653 & 0.9706 \\
\hline Yes & 0.8795 & $0.6879-0.9614$ & 94 & 0.8209 & 0.8889 \\
\hline Type of aortic aneurysm & & & & & \\
\hline Abdominal aortic aneurysm & 0.9233 & $0.8440-0.9649$ & 65.5 & 0.8438 & 1.0000 \\
\hline Thoracic aortic aneurysm & 0.8660 & $0.7961-0.9090$ & 58.5 & 0.6391 & 0.9643 \\
\hline
\end{tabular}

Abbreviations: APACHE, Acute Physiology And Chronic Health Evaluation; ICU, intensive care unit; AUC, Area under the Receiver operating characteristic curve; $\mathrm{Cl}$, confidence interval.

\section{Figures}


elCU Collaborative Research Database

139367 unique patients (166355 unique hospitalizations; 200859 unique ICU hospitalizations)

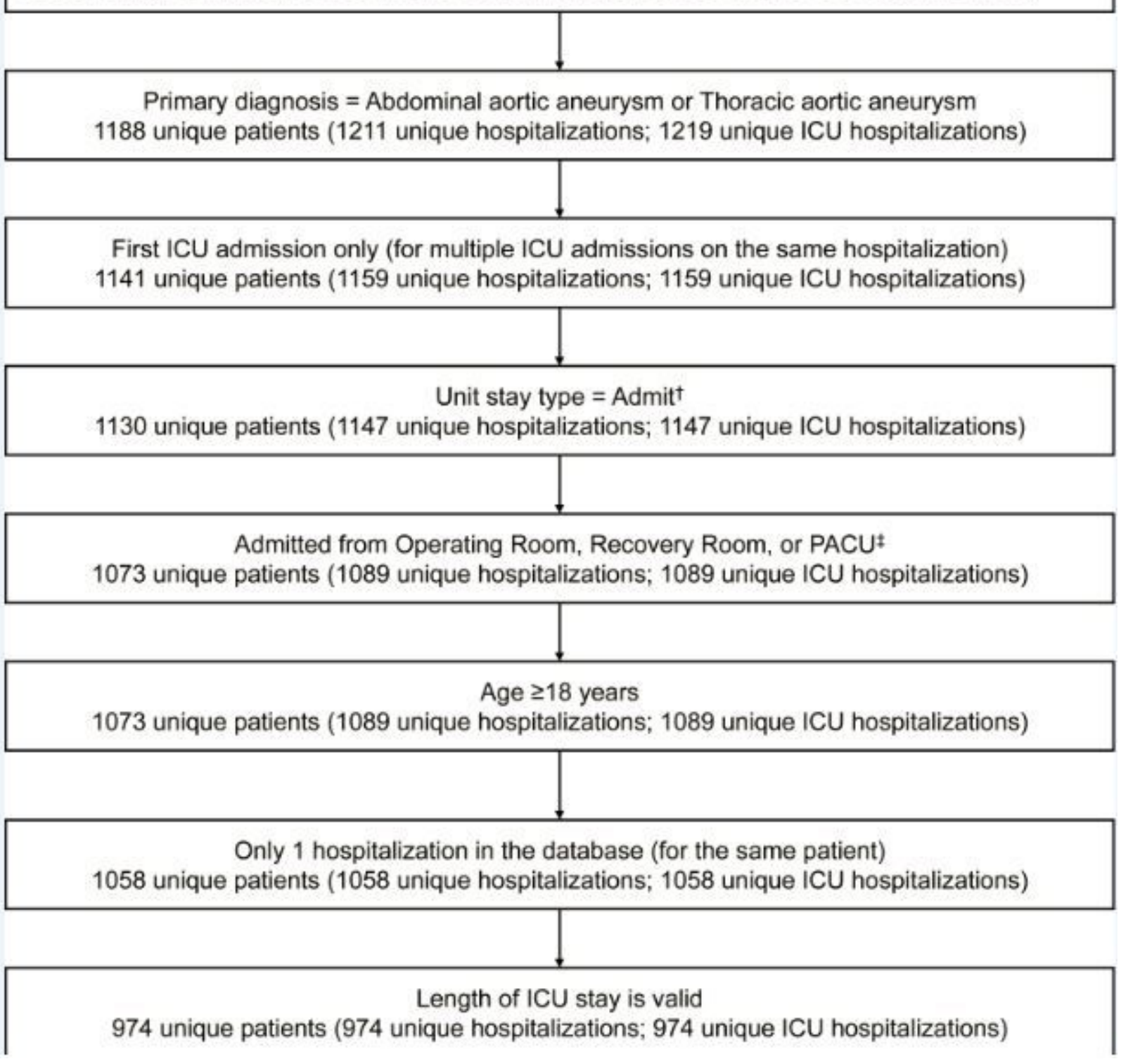

\section{Figure 1}

1) instead of "admit", patients with an ICU stay type of "stepdown/other", "readmit for undo", "pre-admit", "transfer", or "readmit"; 2) patients who had more than 1 hospitalization records in the database; 3 ) length of ICU stay is missing. Flow chart of the study population was presented 


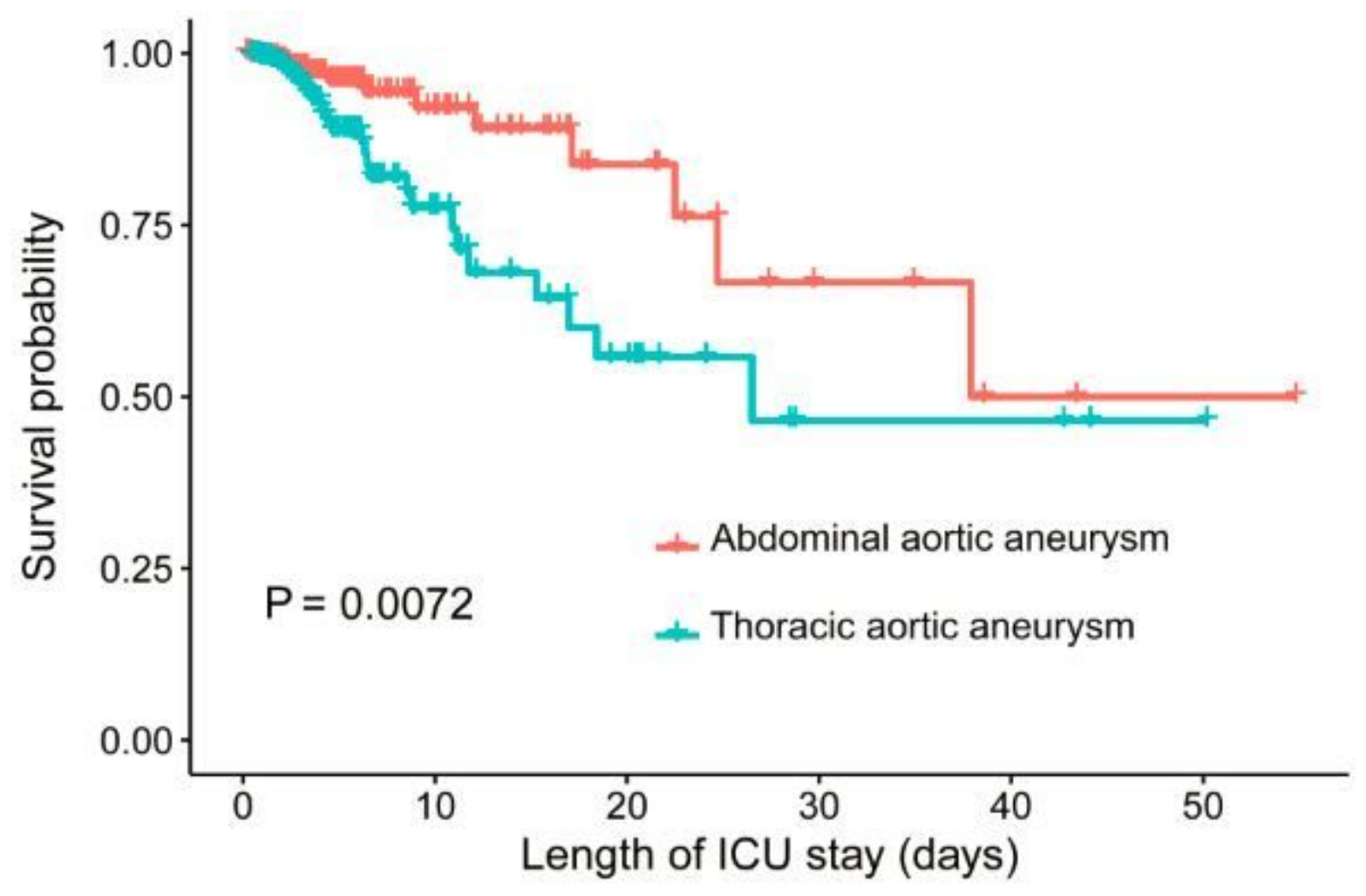

\begin{tabular}{|c|c|c|c|c|c|}
\hline 677 & 37 & 13 & 5 & 2 & 1 \\
\hline 297 & 30 & 12 & 3 & 3 & 1 \\
\hline 0 & 10 & 20 & 30 & 40 & 50 \\
\hline
\end{tabular}

Figure 2

which showed a poorer survival in TAA patients compared with AAA patients $(P=0.0072)$. When the study population was categorized based on length of ICU stay ( $<2$ days, 2-7 days, and $\geq 7$ days), patients with longer length of ICU stay had worse prognosis 